\title{
Dynamic interventions to control COVID-19 pandemic: a multivariate prediction modelling study comparing 16 worldwide countries
}

\author{
Rajiv Chowdhury ${ }^{1}$ (D) Kevin Heng ${ }^{2,3} \cdot$ Md Shajedur Rahman Shawon $^{4} \cdot$ Gabriel Goh $^{5}$ - Daisy Okonofua ${ }^{1}$. \\ Carolina Ochoa-Rosales ${ }^{6,7} \cdot$ Valentina Gonzalez-Jaramillo $^{8} \cdot$ Abbas Bhuiya $^{9} \cdot$ Daniel Reidpath $^{10}$. \\ Shamini Prathapan ${ }^{11}$. Sara Shahzad ${ }^{1}$. Christian L. Althaus ${ }^{8}$. Nathalia Gonzalez-Jaramillo ${ }^{8}$. Oscar H. Franco ${ }^{8}$ on \\ behalf of The Global Dynamic Interventions Strategies for COVID-19 Collaborative Group
}

Received: 30 April 2020 / Accepted: 9 May 2020 / Published online: 19 May 2020

(c) The Author(s) 2020

\begin{abstract}
To date, non-pharmacological interventions (NPI) have been the mainstay for controlling the coronavirus disease-2019 (COVID-19) pandemic. While NPIs are effective in preventing health systems overload, these long-term measures are likely to have significant adverse economic consequences. Therefore, many countries are currently considering to lift the NPIs-increasing the likelihood of disease resurgence. In this regard, dynamic NPIs, with intervals of relaxed social distancing, may provide a more suitable alternative. However, the ideal frequency and duration of intermittent NPIs, and the ideal "break" when interventions can be temporarily relaxed, remain uncertain, especially in resource-poor settings. We employed a multivariate prediction model, based on up-to-date transmission and clinical parameters, to simulate outbreak trajectories in 16 countries, from diverse regions and economic categories. In each country, we then modelled the impacts on intensive care unit (ICU) admissions and deaths over an 18-month period for following scenarios: (1) no intervention, (2) consecutive cycles of mitigation measures followed by a relaxation period, and (3) consecutive cycles of suppression measures followed by a relaxation period. We defined these dynamic interventions based on reduction of the mean reproduction number during each cycle, assuming a basic reproduction number $\left(R_{0}\right)$ of 2.2 for no intervention, and subsequent effective reproduction numbers $(R)$ of 0.8 and 0.5 for illustrative dynamic mitigation and suppression interventions, respectively. We found that dynamic cycles of 50-day mitigation followed by a 30-day relaxation reduced transmission, however, were unsuccessful in lowering ICU hospitalizations below manageable limits. By contrast, dynamic cycles of 50-day suppression followed by a 30-day relaxation kept the ICU demands below the national capacities. Additionally, we estimated that a significant number of new infections and deaths, especially in resource-poor countries, would be averted if these dynamic suppression measures were kept in place over an 18-month period. This multi-country analysis demonstrates that intermittent reductions of $R$ below 1 through a potential combination of suppression interventions and relaxation can be an effective strategy for COVID-19 pandemic control. Such a "schedule" of social distancing might be particularly relevant to low-income countries, where a single, prolonged suppression intervention is unsustainable. Efficient implementation of dynamic suppression interventions, therefore, confers a pragmatic option to: (1) prevent critical care overload and deaths, (2) gain time to develop preventive and clinical measures, and (3) reduce economic hardship globally.
\end{abstract}

Keywords COVID-19 $\cdot$ Prediction modelling $\cdot$ Dynamic interventions $\cdot$ Infectious disease $\cdot$ Epidemiology

Rajiv Chowdhury and Kevin Heng are joint first authors; Christian L. Althaus, Nathalia Gonzalez-Jaramillo and Oscar H. Franco are joint final authors.

Electronic supplementary material The online version of this article (https://doi.org/10.1007/s10654-020-00649-w) contains supplementary material, which is available to authorized users.

Extended author information available on the last page of the article

\section{Introduction}

Coronavirus disease 2019 (COVID-19) pandemic has imposed an unprecedented challenge to global healthcare systems, societies, and governments [1]. As of May 16, 2020, the severe acute respiratory syndrome coronavirus-2 (SARS-CoV-2, causative pathogen for COVID-19) has been detected in every country, with more than 4.6 million 
confirmed cases and a death toll exceeding 300,000 worldwide [2]. Furthermore, recent pandemic model projections estimate that COVID-19 could result in $\sim 40$ million deaths globally this year, if no interventions are implemented [3]. To date, in the absence of efficacious pharmaceutical measures for prevention or treatment, the principal strategy to control COVID-19 has focused on communitybased, non-pharmaceutical interventions (NPIs) [4]. These NPIs typically include a package of mitigation and suppression measures (e.g., case-based isolation, shielding of vulnerable groups, school closures, restricting public events and lockdowns), that aim to minimize person-toperson transmissions of SARS-CoV-2 through social distancing [5].

While NPIs are effective (e.g., in blunting the peak of the epidemic, preventing health systems overload and reducing incidence) $[4,6,7]$, these long-term measures are also associated with significant unemployment, economic hardship and social disruption (with surveys from resource-poor settings showing an average fall in income by $70 \%$ and consumption expenditure by $30 \%$ ) [8]. There is a growing concern whether these prolonged interventions are sustainable given the widespread disparities in economic resilience and health sector capacities globally [9]. As a result, many countries worldwide are currently considering to lift the lockdowns-increasing the likelihood of disease resurgence. In this regard, dynamic NPIs with intervals of relaxed social distancing, may serve as a realistic alternative to achieve the NPI goals, with minimal adverse socioeconomic consequences. However, it remains unclear (1) what should be the frequency and duration of such dynamic NPIs, (2) what should be the ideal "break" when interventions can be relaxed temporarily before case numbers resurge, and (3) which dynamic NPI strategy should be adapted globally across regions with diverse health and economic infrastructures. Addressing these issues is essential to devise feasible, contextspecific policies to prevent collapse of healthcare systems, reduce premature deaths and minimize detrimental impacts on national economies associated with prolonged continuous NPIs.

To address these uncertainties, we have employed a transmission dynamic model comparing sixteen countries that vary in setting and income groupings. Our key aims were to: (1) calculate age-standardized estimates of caseseverity and fatality in included countries; (2) estimate the impact of an uncontrolled course of the pandemic in each country, given the current resources of their health systems (counterfactual), (3) compare continuous versus intermittent combinations of mitigation/suppression and relaxation strategies, over an 18-month period (i.e., optimistic timeline for an efficacious vaccine to be developed [10]); and (4) identify strategies that help keep the number of projected cases requiring critical care within a manageable limit, while also considering a feasible duration of these interventions.

\section{Methods}

This study was conducted according to the to the TRIPOD reporting guideline [11] for prediction modelling studies (Supplementary Appendix 1).

\section{Study design, source of data and study settings}

We have employed a multivariate prediction model to describe COVID-19 transmission dynamics under various NPIs. Since the distributions of age and underlying comorbidities may differ importantly by country, region and economic status [4] we have hypothesised that the predicted mortality impacts for NPI strategies will differ importantly. Therefore, for this current study, we have considered several circumstances. First, we used age-standardized clinical dynamic estimates to model the epidemic trajectories in 16 different countries (which comprise roughly a quarter of the global population), by accessing available country-specific age structure data. Second, we selected these countries from diverse geographical regions: Western Europe (The Netherlands, Belgium), South America (Chile, Colombia), North America (Mexico), Africa (South Africa, Nigeria, Ethiopia, Tanzania, Uganda), South Asia (India, Bangladesh, Pakistan Sri Lanka), West Asia (Yemen), and the Pacific (Australia). Third, these countries also represent all income categories equally, as defined by the World Bank [12]: four countries in every high (HIC), higher-middle (HMIC), lower-middle (LMIC) and low income (LIC) groups, respectively.

\section{Intervention scenarios, predictors and outcomes}

We considered case isolation at home, voluntary home quarantine, closure of schools and universities, and social distancing of the entire population as physical distancing measures. We defined the study interventions scenarios based on reduction of the reproduction number during the duration of intervention $(R)$. For this, we assumed a basic reproduction number [13] $\left(R_{0}\right.$, the average number of secondary infections arising from a typical single infection in a completely susceptible population) of 2.2 for uncontrolled spread of COVID-19, and effective reproduction numbers ( $R$, average number of secondary cases per infectious case in presence of control measures and a partially immune population) of 0.8 and 0.5 for mitigation and suppression interventions, respectively. These assumptions were based 
on recent work by Jarvis et al. [14] who reported a $73 \%$ reduction in the average daily number of contacts observed per participant for physical distancing measures. This corresponded to a pre-intervention $R_{0}$ value of 2.6 to reduce to a post-intervention $R$ value of 0.62 (95\% confidence interval: 0.37-0.89) following strict suppression measures. Even though the exact relationship between changes in the number of social contacts and $R_{0}$ remains unclear, we used these findings as the rationale to calculate our study's effective $R$ values of 0.5 and 0.8 for the interventions. These numbers are in agreement with recent estimates for several European countries and arguably reflect the expected effects of a somewhat relaxed and more stringent lockdown [15].

Based on this approach, or each country, the following intervention scenarios were considered: (1) no intervention (i.e., counterfactual scenario), (2) consecutive cycles of mitigation (a combination of measures, such as general social distancing measures, hygiene rules, case-based isolation, shielding of vulnerable groups, school closures or restricting of large public events; target $R=0.8$ ), followed by a relaxation period (comprising of case-based home isolation of positive cases and shielding of vulnerable groups), (3) consecutive cycles of suppression (additional measures of strict physical distancing, including lockdowns; target $R=0.5$ ) followed by a relaxation period (as defined above), and (4) a continuous suppression measure with no relaxation.

In the absence of intervention, the assumed parameters for transmission dynamics yielded a characteristic rise-andfall timescale of infections of about 50 days, which we set to be the illustrative duration of intervention. Choosing a slightly longer period (e.g. 60 days) yielded similar outcomes. The duration of breaks between interventions needs to be less than the intervention period for the interventions to be effective; therefore, we set the break duration to be 30 days. When to intervene was determined by the initial fraction of the population that was infected. For example, if the fraction was on the order of 1 part in 10,000 (or more), we set the initiation point for the intervention at Day 20. However, if the fraction was on the order of 1 part in 100,000 to 1 million, we set the initiation point as Day 30. Similarly, if the fraction was on the order of 1 part in 10 million, we set this at Day 50. Changes in the initial fraction simply shift the curves back and forth in time without altering their shapes.

For each country, the outcomes of interest were (1) the number requiring intensive care unit (ICU) beds (primary outcome); and (2) total number of hospitalizations and deaths (secondary outcome), by different scenarios of NPIs, and within a time horizon of 18 months. We prioritized ICU care needs as the main outcome since this healthcare component is in short supply in many resource-limited settings, and therefore, is a major determinant for adverse COVID-19 outcomes.

\section{Statistical methods for model calibration and age-standardization}

The analyses were based on a standard susceptibleexposed-infected-recovered (SEIR) compartmental model [16] to describe the transmission of SARS-CoV-2 in 16 countries under various NPI scenarios. The model considered additional compartments for hospitalization and ICU demand. Susceptible individuals $S$ are infected by infectious individuals $I$ at a rate $\beta$. After an incubation period of $1 / \sigma=5 \cdot 2$ days [17], exposed individuals $E$ becomes infectious $I$, and either clear the infection at a rate $\gamma$ or progress to severe infection $P$ with probability $f_{P}$. The infectious period is taken to be $1 / \gamma=2 \cdot 3$ days, corresponding to a serial interval and generation time of $1 / \sigma+1 / \gamma=7 \cdot 5$ days [17]. The quantity $f_{P}$ is the proportion of infections that require hospitalization, for which we obtained age-specific estimates from a recent analysis of COVID-19 cases in China [18].

We applied these age-specific estimates to each individual country's population to get country-specific agestandardized proportion of infections that require hospitalization. We considered the delay between severe infection and hospitalization is $1 / \omega=2.7$ days [4]. Severely infected individuals $P$ enter the hospital as $H$, after which they either leave the hospital at a rate $\kappa$ or enter the ICU with probability $f_{U}$. Age-stratified proportions of hospitalized cases requiring ICU care $\left(f_{U}\right)$ were based on the Imperial College COVID-19 Response Team's Report [4], and then standardized according to each country's population age structure. The quantity $1 / \kappa$ is the duration of non-ICU hospital stays, which we considered 8 days [4]. Patients $U$ stay in ICU for $1 / \delta=8$ days [4], after which a fraction of them die $\left(f_{D}\right)$. The age-specific infectious fatality rate (IFR) were obtained from Verity et al. [18]. Those were subsequently applied to individual country's population to get country-specific age-standardized IFRs (Supplementary Tables S1-S16). IFR is the product of $f_{P}, f_{U}$, and $f_{D}$. The basic reproduction number is $R_{0}=\beta N / \gamma=2 \cdot 2[17,19,20]$, with $N$ being the total population size of the country. The set of coupled ordinary differential equations that underpin our model are

Box 1 Equations used in SEIR compartmental model

$$
\begin{aligned}
& \frac{d S}{d t}=-\beta I S, \\
& \frac{d E}{d t}=\beta I S-\sigma E \\
& \frac{d I}{d t}=\sigma E-\gamma I \\
& \frac{d P}{d t}=f_{P} \gamma I-\omega P \\
& \frac{d H}{d t}=\omega P-\kappa H \\
& \frac{d U}{d t}=f_{U} \kappa H-\delta U \\
& \frac{d R}{d t}=\left(1-f_{P}\right) \gamma I+\left(1-f_{U}\right) \kappa H+\left(1-f_{D}\right) \delta U, \\
& \frac{d D}{d t}=f_{D} \delta U
\end{aligned}
$$


presented in the Box 1. These equations in the SEIR model were solved numerically using the solve_ivp package in the Python programming language suite [21]; plots were created using the matplotlib graphics package [22].

\section{Results}

\section{Country-specific characteristics and clinical dynamics}

Demographic and health system-related characteristics Table 1 presents a summary of the demographic and health system-related characteristics for the included countries, grouped by their respective income levels. Briefly, the countries varied in population size (ranging from 11,539,326 in Belgium to 1,366,417,755 in India).
The first cases were identified in a much later date in the LICs ( late February-early March, 2020) compared to HIC countries such as Australia, the Netherlands and Belgium. Additionally, there were significant differences across countries with respect to healthcare infrastructure. For example, in the majority of LICs and LMICs, available hospital and ICU beds were $<1$ bed per 1000 population and $<1$ bed per 100,000 population, respectively (Table 1).

Age-standardized estimates of case-severity and fatality Table 2 summarizes various COVID-19 relevant clinical dynamics estimated for each of the 16 included countries. Briefly, proportion of infected individuals who require hospitalization ranged from $1.61 \%$ in Uganda to $6.12 \%$ in the Netherlands, with higher proportions observed in HIC and UMICs compared to the other country categories. This pattern was similar for the proportion of hospitalized

Table 1 Key demographic and health system-related characteristics of the 16 included countries

\begin{tabular}{|c|c|c|c|c|c|c|c|}
\hline & $\begin{array}{l}\text { Size of popula- } \\
\text { tion }\end{array}$ & $\begin{array}{l}\text { Number of } \\
\text { initial infections } \\
(\text { as of } 1 \text { April } \\
2020)^{\mathrm{a}}\end{array}$ & $\begin{array}{l}\text { Date of first } \\
\text { case }\end{array}$ & $\begin{array}{l}\text { Hospital beds } \\
\text { per } 1000 \\
\text { population }^{\mathrm{b}}\end{array}$ & $\begin{array}{l}\text { Total hospital } \\
\text { beds }\end{array}$ & Total ICU beds $^{\mathrm{c}}$ & $\begin{array}{l}\text { ICU beds per } \\
100,000 \text { popu- } \\
\text { lation }\end{array}$ \\
\hline \multicolumn{8}{|l|}{ High-income } \\
\hline Australia & $25,203,200$ & 9618 & 25 January 2020 & 3.8 & 95,772 & 2200 & 8.7 \\
\hline Belgium & $11,539,326$ & 11,899 & $\begin{array}{l}\text { 04 February } \\
2020\end{array}$ & 6.2 & 71,544 & 1900 & 16.5 \\
\hline Chile & $18,952,035$ & 2449 & 03 March 2020 & 2.2 & 41,694 & 1000 & 5.3 \\
\hline $\begin{array}{l}\text { The Nether- } \\
\text { lands }\end{array}$ & $17,097,123$ & 11,750 & $\begin{array}{l}27 \text { February } \\
2020\end{array}$ & 4.7 & 80,356 & 1150 & 6.7 \\
\hline \multicolumn{8}{|c|}{ Upper-middle income } \\
\hline Colombia & $50,339,443$ & 702 & 06 March 2020 & 1.5 & 75,509 & 5600 & 11.1 \\
\hline Mexico & $127,575,528$ & 993 & $\begin{array}{l}28 \text { February } \\
2020\end{array}$ & 1.5 & 191,363 & 3000 & 2.4 \\
\hline South Africa & $58,558,267$ & 1326 & 05 March 2020 & 2.5 & 146,396 & 1500 & 2.6 \\
\hline Sri Lanka & $21,323,734$ & 112 & 27 January 2020 & 3.6 & 76,765 & 519 & 2.4 \\
\hline \multicolumn{8}{|c|}{ Lower-middle income } \\
\hline Bangladesh & $163,046,173$ & 49 & 08 March 2020 & 0.8 & 130,437 & 1174 & 0.7 \\
\hline India & $1,366,417,755$ & 1251 & 30 January 2020 & 0.9 & $1,229,776$ & 29,997 & 2.2 \\
\hline Nigeria & $200,963,603$ & 111 & $\begin{array}{l}27 \text { February } \\
2020\end{array}$ & 0.5 & 100,482 & 128 & 0.1 \\
\hline Pakistan & $216,565,317$ & 1865 & $\begin{array}{l}26 \text { February } \\
2020\end{array}$ & 0.6 & 129,939 & 3142 & 1.5 \\
\hline \multicolumn{8}{|l|}{ Low-income } \\
\hline Afghanistan & $38,041,757$ & 166 & $\begin{array}{l}\text { 24 February } \\
2020\end{array}$ & 0.5 & 19,021 & 100 & 0.3 \\
\hline Burkina Faso & $20,321,383$ & 246 & 09 March 2020 & 0.4 & 8,129 & 50 & 0.2 \\
\hline Tanzania & $58,005,461$ & 19 & 16 March 2020 & 0.7 & 40,604 & 38 & 0.1 \\
\hline Uganda & $44,269,587$ & 33 & 20 March 2020 & 0.5 & 22,135 & 55 & 0.1 \\
\hline
\end{tabular}

$I C U$ intensive care unit

${ }^{a}$ Taken from various country-specific reports

${ }^{\mathrm{b}}$ Taken from The World Bank Data on hospital bed [23]

${ }^{\mathrm{c}}$ Taken from various country-specific reports 
Table 2 Age-standardised estimates for case severity and fatality of COVID-19 for 16 included countries

\begin{tabular}{|c|c|c|c|c|}
\hline & $\begin{array}{l}\text { Proportion of infected indi- } \\
\text { viduals hospitalised }^{\mathrm{a}}(\%)\end{array}$ & $\begin{array}{l}\text { Proportion of hospitalised cases } \\
\text { requiring critical care } \mathrm{e}^{\mathrm{b}}(\%)\end{array}$ & $\begin{array}{l}\text { Proportion of individuals requir- } \\
\text { ing critical care } \operatorname{die}^{c}(\%)\end{array}$ & $\begin{array}{l}\text { Infection fatality } \\
\text { ratio }(I F R)^{\mathrm{d}}(\%)\end{array}$ \\
\hline \multicolumn{5}{|l|}{ High-income } \\
\hline Australia & 5.34 & 29.3 & 59.6 & 0.93 \\
\hline Belgium & 6.01 & 31.5 & 59.6 & 1.13 \\
\hline Chile & 4.69 & 25.8 & 59.5 & 0.72 \\
\hline The Netherlands & 6.12 & 30.6 & 59.6 & 1.12 \\
\hline \multicolumn{5}{|c|}{ Upper-middle income } \\
\hline Colombia & 3.93 & 23.3 & 59.4 & 0.54 \\
\hline Mexico & 3.57 & 22.3 & 59.4 & 0.47 \\
\hline South Africa & 3.09 & 19.1 & 59.2 & 0.35 \\
\hline Sri Lanka & 4.38 & 24.2 & 59.5 & 0.63 \\
\hline \multicolumn{5}{|c|}{ Lower-middle income } \\
\hline Bangladesh & 3.10 & 19.6 & 59.3 & 0.36 \\
\hline India & 3.35 & 20.3 & 59.3 & 0.41 \\
\hline Nigeria & 1.96 & 16.3 & 59.1 & 0.19 \\
\hline Pakistan & 2.55 & 19.0 & 59.2 & 0.29 \\
\hline \multicolumn{5}{|l|}{ Low-income } \\
\hline Afghanistan & 1.86 & 16.4 & 59.1 & 0.18 \\
\hline Burkina Faso & 1.81 & 16.0 & 59.0 & 0.17 \\
\hline Tanzania & 1.90 & 16.3 & 59.0 & 0.18 \\
\hline Uganda & 1.61 & 15.1 & 58.9 & 0.15 \\
\hline
\end{tabular}

All estimates are standardised according to the age structure of the respective country

${ }^{a}$ Age-specific proportions of infected individuals hospitalised were taken from Verity et al. [18]. These proportions were adjusted for underascertainment and corrected for demography. We assumed that cases defined as severe would be hospitalised

${ }^{\mathrm{b}}$ Age-specific proportions of hospitalised cases requiring critical care were taken from Imperial COVID-19 Response Team Report [4]

${ }^{\mathrm{c}}$ Age-specific proportions of individuals requiring critical care die were calculated by dividing the IFRs with proportions of infected individuals hospitalised and proportions of hospitalised cases requiring critical care

${ }^{\mathrm{d}}$ Age-specific IFRs were taken from Verity et al. [18]

cases requiring critical care (Table 2). IFR estimates were significantly higher in the HICs, compared to LMIC and LICs (range 0.17 in Burkina Faso to 1.13 in Belgium).

\section{Model development and predicted impact of the interventions}

Impact of uncontrolled or no intervention scenario In the unlikely scenario of no NPI, the number of cases requiring ICU care would exceed the available capacity significantly for every single country (Fig. 1). This unmitigated scenario, in aggregate, would also result in 7,840,444 deaths in all 16 countries. This estimate would have been equivalent to approximately $46 \%$ of all deaths recorded in these countries in 2017. Additionally, an uncontrolled epidemic would predict 583,738 total deaths in the HIC, 1,026,361 deaths in the HMIC, 6,000,220 deaths in the LMIC, and 230,125 deaths in the LIC settings. The majority of these deaths will occur in India, proportionate to the large population of this country. Under this scenario, the duration of the epidemic will last nearly 200 days in the majority of the included countries (Fig. 1).

Comparing impacts of dynamic cycles of mitigation/ suppression and relaxation Our models predict that simultaneous cycles of 50-day mitigation intervention followed by a 30-day relaxation would likely to reduce the effective reproduction number $R$ to 0.8 in all countries. However, this rolling mitigation measure was insufficient to keep the number of patients requiring healthcare below the available critical care capacity (Fig. 1). In this NPI scenario, the duration of pandemic appeared approximately 12 months in the HIC, and was close to 18 months in the other settings. Additionally, dynamic mitigation interventions were effective at the first 3 months for all the countries, but after the first relaxation, the pandemic would exceed the hospital capacity in all the countries and would result in 3,534,793 deaths. By contrast, we found that dynamic cycles of 50-day suppression followed by a 30-day relaxation, aimed at reducing the effective $R$ to 0.5 , were suitable for all settings to keep ICU demand within national capacity (Fig. 1). Since more individuals remain susceptible at 

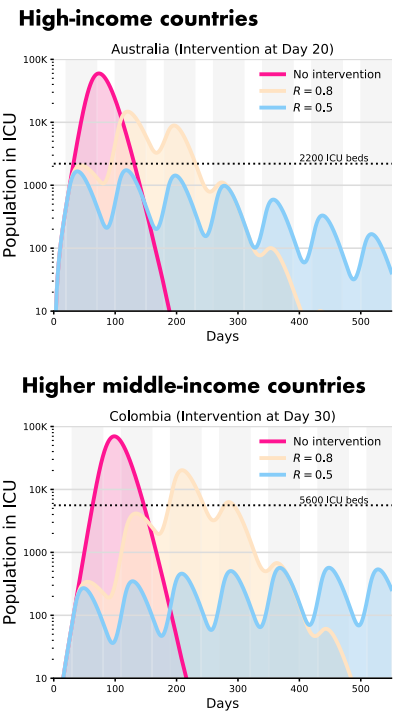

Lower middle-income countries
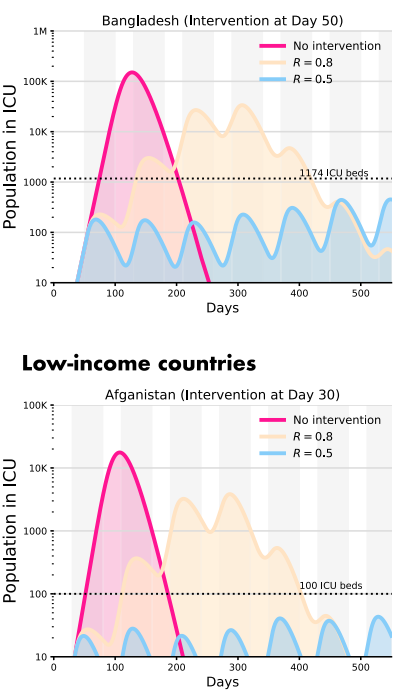
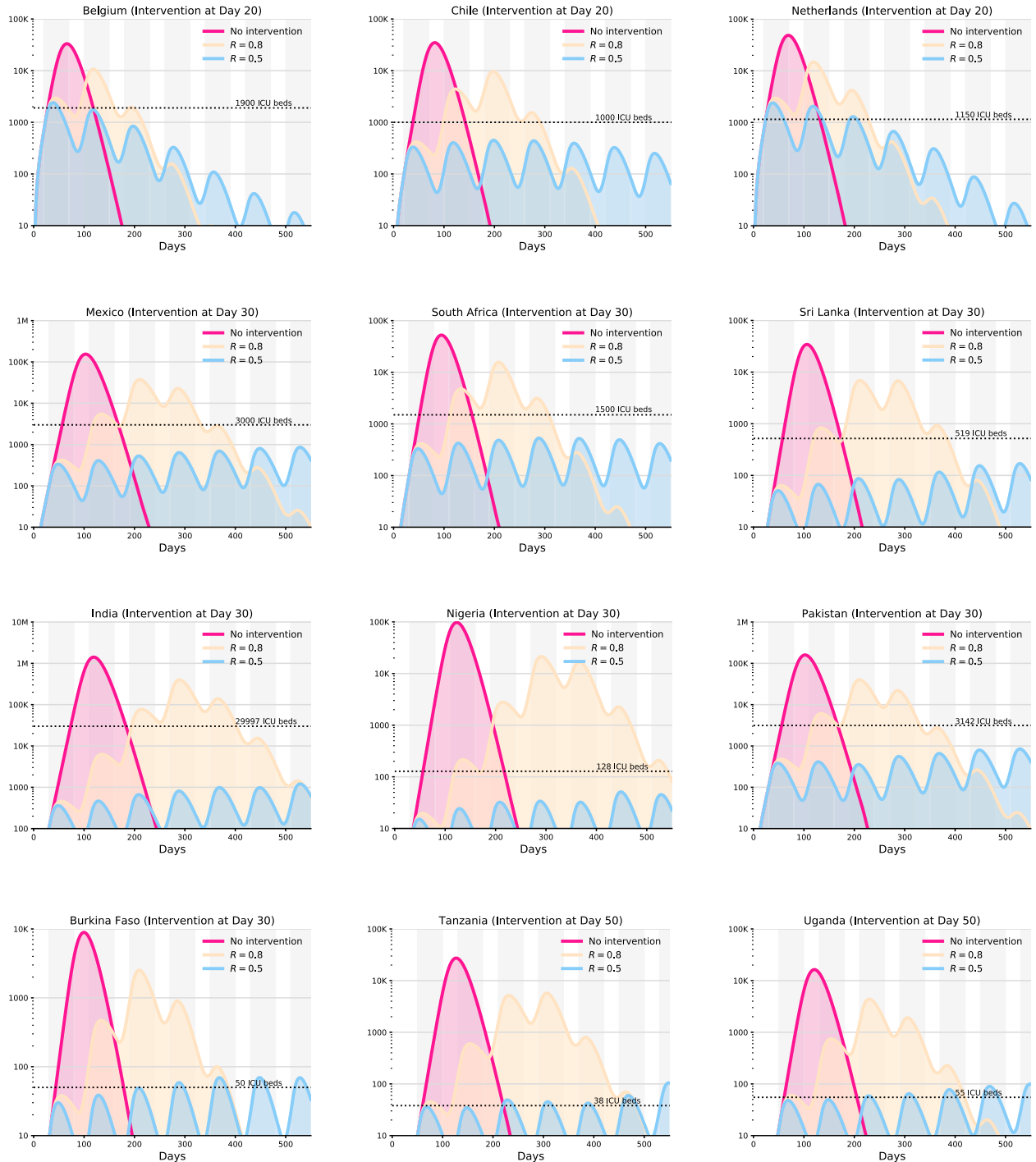

Fig. 1 Impact of dynamic interventions and relaxation on ICU beds requirement in 16 countries over an 18-month period

the end of each cycle of suppression and relaxation, such approach would result in a longer pandemic, beyond 18 months in all countries; however, global mortality would drop to 131,643 during that period (Fig. 1).

Estimated impacts of dynamic mitigation and suppression strategies on new infections, hospitalisations and deaths in all 16 countries have been summarised in Table 3. Briefly, the numbers of new infections per day (during the peak of epidemic) were significantly higher for all countries in no and dynamic mitigation intervention scenarios. Both new infections and ICU bed requirements per day (during the peak of epidemic) were significantly lower, especially for low-income settings, for dynamic suppression and relaxation strategy (Table 3). For dynamic mitigation strategies, mortality estimates were 266,835 in HICs, 463,499 in HMICs, 2,700,162 in LMICs, were and 104,297 in LICs. The corresponding estimates for the dynamic suppression strategies were markedly lower: 63,166 in HICs, 32,419 in HMICs, 32,210 in LMICs and 3,848 in LICs (Table 3).

Sensitivity analyses As sensitivity analyses, we found that a single but continuous yearlong mitigation or suppression strategy would be effective to keep the number of patients well below the available hospital capacity (Fig. 2). In case of suppression, in 3 months, most of the countries would not have any new cases to report. In case of sustained mitigation, countries would require approximately 6.5 months to reach a no-new-case scenario (Fig. 2). Additionally, dynamic mitigation and suppression interventions implemented for a period of time less than 50 days led to an increase in the number of infections beyond the ICU healthcare capacities. The 
Table 3 The estimated impacts of various interventions on COVID-19 outcomes in 16 countries

\begin{tabular}{|c|c|c|c|c|c|c|c|c|c|}
\hline \multirow[t]{2}{*}{$\begin{array}{l}\text { Countries } \\
\text { and income } \\
\text { categories }\end{array}$} & \multicolumn{3}{|c|}{ Uncontrolled, no intervention scenario } & \multicolumn{3}{|c|}{$\begin{array}{l}\text { Intermittent cycles of mitigation and } \\
\text { relaxation } \\
\text { (Effective } R=0.8 \text { ) }\end{array}$} & \multicolumn{3}{|c|}{$\begin{array}{l}\text { Intermittent cycles of suppression and } \\
\text { relaxation } \\
\text { (Effective } R=0.5 \text { ) }\end{array}$} \\
\hline & $\begin{array}{l}\text { New infec- } \\
\text { tions/day } \\
\text { during the } \\
\text { peak }\end{array}$ & $\begin{array}{l}\text { ICU bed } \\
\text { needs/day } \\
\text { during the } \\
\text { peak }\end{array}$ & $\begin{array}{l}\text { No. of total } \\
\text { deaths over } \\
18 \text { months }\end{array}$ & $\begin{array}{l}\text { New infec- } \\
\text { tions/day } \\
\text { during the } \\
\text { peak }\end{array}$ & $\begin{array}{l}\text { ICU bed } \\
\text { needs/day } \\
\text { during the } \\
\text { peak }\end{array}$ & $\begin{array}{l}\text { No. of total } \\
\text { deaths over } \\
18 \text { months }\end{array}$ & $\begin{array}{l}\text { New infec- } \\
\text { tions/day } \\
\text { during the } \\
\text { peak }\end{array}$ & $\begin{array}{l}\text { ICU bed } \\
\text { needs/day } \\
\text { during the } \\
\text { peak }\end{array}$ & $\begin{array}{l}\text { No. of total } \\
\text { deaths over } \\
18 \text { months }\end{array}$ \\
\hline \multicolumn{10}{|l|}{ High-income } \\
\hline Australia & $1,434,638$ & 59,803 & 197,746 & 418,643 & 14,798 & 89,091 & 54,748 & 1734 & 19,996 \\
\hline Belgium & 657,883 & 33,213 & 109,785 & 253,150 & 10,674 & 51,151 & 63,135 & 2404 & 15,846 \\
\hline Chile & $1,078,061$ & 34,818 & 115,060 & 357,316 & 9716 & 53,210 & 18,351 & 450 & 7505 \\
\hline $\begin{array}{l}\text { The Neth- } \\
\text { erlands }\end{array}$ & 973,779 & 48,724 & 161,147 & 354,373 & 14,831 & 73,383 & 63,412 & 2395 & 19,819 \\
\hline \multicolumn{10}{|c|}{ Upper-middle income } \\
\hline Colombia & $2,862,000$ & 69,878 & 230,682 & 988,841 & 20,225 & 104,040 & 30,730 & 570 & 9239 \\
\hline Mexico & $7,253,642$ & 154,507 & 509,794 & $2,082,308$ & 37,598 & 228,879 & 53,308 & 863 & 12,047 \\
\hline $\begin{array}{l}\text { South } \\
\text { Africa }\end{array}$ & $3,329,773$ & 52,421 & 172,416 & $1,189,739$ & 15,674 & 79,091 & 44,377 & 531 & 9094 \\
\hline Sri Lanka & $1,212,623$ & 34,335 & 113,469 & 282,813 & 6876 & 51,489 & 7875 & 170 & 2039 \\
\hline \multicolumn{10}{|c|}{ Lower-middle income } \\
\hline Bangladesh & $9,270,170$ & 150,503 & 495,420 & $2,427,104$ & 33,631 & 226,700 & 36,597 & 452 & 4908 \\
\hline India & $77,698,771$ & $1,414,384$ & $4,660,013$ & $26,185,375$ & 399,982 & $2,093,893$ & 87,558 & 1211 & 15,379 \\
\hline Nigeria & $11,426,973$ & 97,411 & 319,598 & $2,944,575$ & 21,424 & 144,049 & 7894 & 51 & 659 \\
\hline Pakistan & $12,316,925$ & 159,636 & 525,189 & $3,653,682$ & 40,072 & 235,520 & 86,084 & 848 & 11,264 \\
\hline \multicolumn{10}{|l|}{ Low-income } \\
\hline $\begin{array}{l}\text { Afghani- } \\
\text { stan }\end{array}$ & $2,163,088$ & 17,640 & 57,851 & 550,669 & 3839 & 26,401 & 6989 & 43 & 614 \\
\hline $\begin{array}{l}\text { Burkina } \\
\text { Faso }\end{array}$ & $1,155,479$ & 8918 & 29,228 & 388,909 & 2519 & 13,154 & 11,838 & 69 & 1080 \\
\hline Tanzania & $3,297,673$ & 27,308 & 89,543 & 809,325 & 5740 & 40,755 & 16,653 & 105 & 905 \\
\hline Uganda & $2,516,788$ & 16,350 & 53,503 & 804,079 & 4397 & 23,987 & 20,095 & 99 & 1249 \\
\hline
\end{tabular}

same was observed for relaxation periods longer than 30 days.

\section{Discussion}

In this mathematical modelling study, we have assessed the potential impact of dynamic community-based NPIs, involving sixteen economically diverse countries, as a pragmatic strategy for controlling the COVID-19 pandemic in order to provide a practical illustration of interventions and strategies implemented to reduce the reproduction rate of COVID-19. Our study has several inter-related findings. First, we show that simultaneous cycles of 50-day mitigation ( $R$ value of 0.8 ) followed by a 30-day relaxation could provide means to reduce the effective reproduction number, however, will be insufficient to keep the number of patients requiring ICU care within manageable levels. Second, by contrast, we found that dynamic cycles of 50-day suppression ( $R$ value of 0.5 ) followed by a 30-day relaxation would be required, for all countries, to keep ICU demands below the national capacities. Third, significant number of new infections and deaths could be prevented if these "rolling" suppression measures can be maintained for an 18-month period, or until a suitable treatment and/or vaccination become available. Finally, a continuous, yearlong suppression strategy may also reduce overall attack rates significantly and appears effective. However, implementation (and socioeconomic sustenance) of such stringent measure could be challenged by its detrimental impacts on population wellbeing and livelihood.

Our findings may have several explanations. First, despite higher rates of contact across older age groups [3], we predict a somewhat lower incidence of ICU hospitalisation and deaths in low-income settings. This can be explained, at least partly, by the demographic differences with a relatively younger average age structure of these populations, and absence of integrated death registration system. However, given the significant inequalities in baseline health, testing capabilities and critical care infrastructure across the 

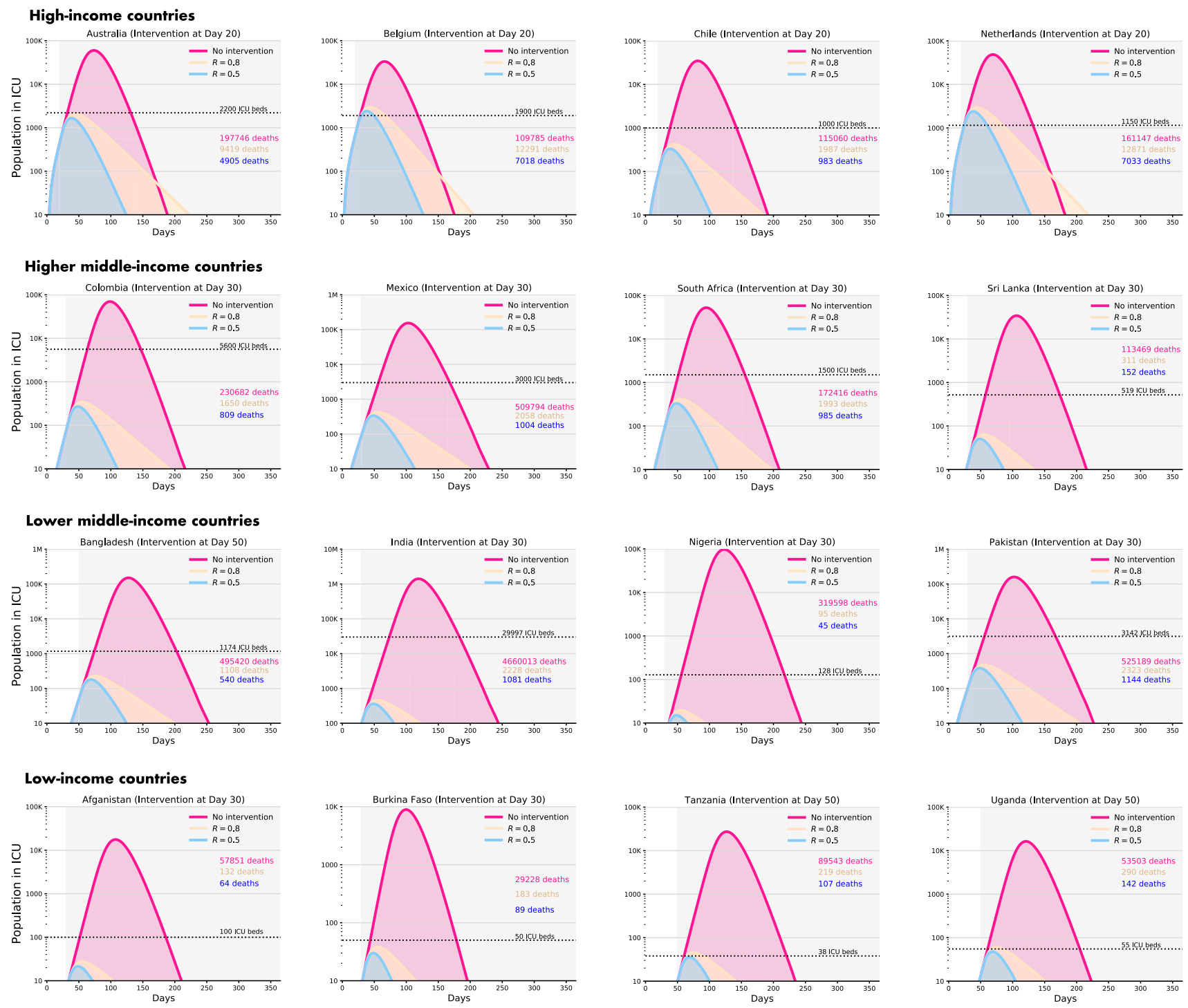

Fig. 2 Impact of single, sustained mitigation or suppression strategy on total deaths in 16 countries over a 12-month period

countries, in reality, a higher overall level of excess deaths are likely in resource-poor settings owing to health systems failure, especially in uncontrolled or mitigation intervention scenarios. Second, it was unsurprising that a more restrictive suppression strategy $(R: 0.5)$ in our study reduced ICU hospitalisations and deaths for all countries. This is because a further reduction in the reproductive number secondary to more stringent interventions can maximally reduce the population transmissibility of the SARS-CoV-2 [24]. Notably, implementation of such strategies also creates a policy dilemma for many low-income countries: how to address the "competing priorities" of preventing COVID-19 associated deaths and public health system failure with the long-term economic collapse and hardship. In this regard, we have observed that in contrast to a long fixed-duration social distancing, dynamic NPIs (that reduce the overall attack rates effectively) may offer a helpful balance.

Third, in our study, dynamic cycles of 50-day suppression followed by a 30-day relaxation were effective to lower the deaths significantly for all countries since both transmissibility and case severity (and by extension, critical care demands) were significantly reduced throughout the 18-month period. Notably, this intermittent combination of strict social distancing, and a relatively relaxed period (with efficient testing, case isolation, contact-tracing and shielding of the vulnerable), may allow populations and the national economies to "breathe" at intervals-a potential that might make this solution more sustainable, especially in resource-poor regions [25]. The specific durations of these interventions can be defined by specific countries according to their needs and local facilities, what is key is to identify a 
combination pattern that allows to protect the health of the population not only from COVID-19 but also from economic hardship and mental health issues. Finally, these findings reinforce the value of dynamic social distancing strategies estimated by earlier studies for the UK, Canada and China $[3,25,26]$, and extend these to multiple global regions under various dynamic intervention scenarios.

The strengths and limitations of our study merit careful consideration. First, as restrictive NPIs may need to be maintained worldwide for many months, we have examined the impacts of dynamic NPIs to "switch on" and "switch off" at regular intervals. These measures have shown to be largely unaffected to uncertainties in effective $R$ estimates and in the severity of the virus [4]. Second, NPI strategies only blunt (however prolong) the epidemic cycle, since there is lesser build-up of herd immunity while these interventions are kept in place. If these measures are, however, lifted altogether, a second (potentially more serious) outbreak could occur [27]. Therefore, in the absence of individuallevel data and more detailed country-specific parameters, our study provides an illustrative comparison of different "rolling" strategies to suggest (a) when such measures could be lifted, and (b) for how long. Third, we used the most upto-date disease transmission parameters $[4,17,18,20]$ to construct our adaptive models, based on well-established SEIR model of epidemic dynamics for infectious diseases. Fourth, since different interventions are likely to be implemented differentially and may have a heterogeneous effect in multiple locations, we have chosen a broad illustrative target of reducing the reproduction number $R$ rather than specific community measures that may differ significantly by context. Fifth, we employed age-standardized estimates of hospitalization and infection-fatality-ratios in countries with diverse demographic structures, and considered countries at various categories of national income, in order to provide useful "context-specific" estimates. Finally, we used rise-and-fall timescale of infections (50 days, in the absence of intervention) as the ideal intervention duration and calculated 30-day as the optimal break duration before triggering the next cycle, however specific to each country other combinations could be considered depending the specific settings and availability of resources. In this regard, triggering dynamic interventions based on a specific pre-specified mortality number or rate, as was done in earlier modelling for the UK [3], would not be optimal for under-developed countries since (a) the health systems are less efficient to ascertain all new cases comprehensively, and (b) a younger demographic would mean that by the time the target mortality threshold is reached for the trigger, the countries have already accrued a significantly large number of cases.

Our study also had several important limitations. In the absence of country-specific, real-time, reproduction numbers for the epidemic, we assumed a constant transmission rate during each modeled cycle. These estimates are likely to vary by a population's adherence to the NPI and the mix of specific measures put in place. In this respect, our chosen effective $R$ estimates of 0.8 and 0.5 reflect two scenarios of weaker and stronger reduction in transmission, respectively, which could be achieved through social distancing measures and the interruption of transmission chains (e.g., through ramping up testing, contact tracing, isolation and quarantine and other potential strategies chosen by individual countries). We anticipate that the countries will be able to introduce additional control measures with time that might counterbalance the detrimental effect of decreasing compliance. The age-standardisation analyses were based on public sector surveillance data, which may not be robust for all LMIC and LIC countries, with potentials for underestimation of cases and deaths. Furthermore, given unavailability of relevant data, we were unable to adjust for wider social and economic costs of the dynamic approaches; further studies will be needed to quantify these aspects. Additional factors such as potential seasonal variations, environmental pollutions or structural determinants may influence, at least in part, these interventions, highlighting the need of flexibility in terms of the suitable strategy and combination of interventions that can be implemented in each country. Finally, similar to all modelling studies, our analyses were based on several transmission parameter assumptions. Since some uncertainties exist around the natural history and local transmission dynamics of the SARS-CoV-2, the precise efficacy and optimal duration of the dynamic strategies may differ for other countries and will need to be tailored accordingly.

Our study may have important implications. First, we have reported several findings relevant to COVID-19 management and policy development. We provide an actionable strategy option for COVID-19 control by employing dynamic interventions that could delay the epidemic peak, while allowing time to enhance health systems capacities and efforts to develop therapies or vaccines. These dynamic measures also allow interim periods of relaxation in order to minimise socioeconomic disruptions and maximise population compliance to these stringent suppression measures. However, these should be weighed carefully against costs, any risks imposed to the society, and the social protection available in each setting. Second, these findings also stimulate further relevant research that may involve: (a) more indepth analyses of detailed natural history of the disease (e.g., including transmissibility in asymptomatic state) based on patient-level data, when available, from various countries [28], (b) various spatial pathways and patterns of epidemic in different circumstances (e.g., co-morbidity, reinfection) and settings (e.g., urban vs. rural); and (c) targeted modelling studies accounting for genomic susceptibility [29], social behaviour [30] and economic diversity [3]. 
In conclusion, this multi-country analysis demonstrates that intermittent reductions of $R$ below 1 through a potential combination of suppression interventions and relaxation can be a pragmatic strategy for COVID-19 pandemic control. Such a "schedule" of social distancing might be particularly relevant to low-income countries, where a single, prolonged suppression intervention is unsustainable. As a policy option, efficient implementation of dynamic suppression interventions worldwide, therefore, would help: (1) prevent critical care overload and deaths, (2) gain time to develop preventive and clinical measures, and (3) reduce economic hardship globally.

Acknowledgements CLA received funding from the European Union's Horizon 2020 research and innovation programme-Project EpiPose (No-101003688). DR was funded by core donors who provide unrestricted support to icddr,b for its operations and research; current donors providing unrestricted support include the Governments of Bangladesh, Canada, Sweden and the UK. We gratefully acknowledge our core donors for their support and commitment to icddr,b's research efforts.

Open Access This article is licensed under a Creative Commons Attribution 4.0 International License, which permits use, sharing, adaptation, distribution and reproduction in any medium or format, as long as you give appropriate credit to the original author(s) and the source, provide a link to the Creative Commons licence, and indicate if changes were made. The images or other third party material in this article are included in the article's Creative Commons licence, unless indicated otherwise in a credit line to the material. If material is not included in the article's Creative Commons licence and your intended use is not permitted by statutory regulation or exceeds the permitted use, you will need to obtain permission directly from the copyright holder. To view a copy of this licence, visit http://creativecommons.org/licenses/by/4.0/.

\section{References}

1. World Health Organization. Coronavirus disease (COVID-2019) situation reports. 2020. https://www.who.int/emergencies/disea ses/novel-coronavirus-2019/situation-reports. Accessed 15 April 2020.

2. The Worldometer. COVID-19 CORONAVIRUS PANDEMIC. 2020. https://www.worldometers.info/coronavirus/. Accessed 15 April 2020

3. Walker PG, Whittaker C, Watson O, et al. The global impact of COVID-19 and strategies for mitigation and suppression. London: WHO Collaborating Centre for Infectious Disease Modelling, MRC Centre for Global Infectious Disease Analysis, Abdul Latif Jameel Institute for Disease and Emergency Analytics, Imperial College London; 2020.

4. Ferguson NM, Laydon D, Nedjati-Gilani G, et al. Impact of nonpharmaceutical interventions (NPIs) to reduce COVID19 mortality and healthcare demand. London: WHO Collaborating Centre for Infectious Disease Modelling MRC Centre for Global Infectious Disease Analysis Abdul Latif Jameel Institute for Disease and Emergency Analytics Imperial College London; 2020.

5. Ainslie KEC, Walters C, Fu H, et al. Evidence of initial success for China exiting COVID-19 social distancing policy after achieving containment. London: WHO Collaborating Centre for Infectious Disease Modelling MRC Centre for Global Infectious
Disease Analysis Abdul Latif Jameel Institute for Disease and Emergency Analytics Imperial College London; 2020.

6. Ahmed F, Zviedrite N, Uzicanin A. Effectiveness of workplace social distancing measures in reducing influenza transmission: a systematic review. BMC Public Health. 2018;18(1):518.

7. Prem K, Liu Y, Russell TW, et al. The effect of control strategies to reduce social mixing on outcomes of the COVID-19 epidemic in Wuhan, China: a modelling study. The Lancet Public Health. 2020;5:e261-70

8. Lora Jones DB, Palumbo D. Coronavirus: a visual guide to the economic impact. BBC News; 2020.

9. United Nations. Inter-agency task force on financing for development, financing for sustainable development report 2020. New York: United Nations; 2020.

10. JAMA Network Learning. Coronavirus (COVID-19) Update: Vaccines and Immunity. In: Poland G, editor; 2020. https://edhub .ama-assn.org/jn-learning/audio-player/18361261. Accessed 15 April 2020.

11. Checklist TRIPODTRIPOD: Prediction Model Development. 2020. https://www.tripod-statement.org/. Accessed 15 April 2020.

12. The World Bank. World Bank country and lending groups. https ://datahelpdesk.worldbank.org/knowledgebase/articles/90651 9-world-bank-country-and-lending-groups. Accessed $30 \mathrm{Mar}$ 2020.

13. Rothman KJ, Lash TSG. Modern Epidemiology. 3rd ed. Philadelphia: Lippincott Williams \& Wilkins; 2013.

14. Jarvis CI, Zandvoort Kv, Gimma A, et al. Impact of physical distance measures on transmission in the UK. CMMID Repository 2020.

15. Flaxman L et al. 2020. https://www.imperial.ac.uk/media/imper ial-college/medicine/mrc-gida/2020-03-30-COVID19-Report-13. pdf. Accessed May 12020

16. Blackwood JC, Childs LM. An introduction to compartmental modeling for the budding infectious disease modeler. Lett Biomath. 2018;5(1):195-221.

17. Li Q, Guan X, Wu P, et al. Early transmission dynamics in Wuhan, China, of novel coronavirus-infected pneumonia. N Engl J Med. 2020;382(13):1199-207.

18. Verity R, Okell LC, Dorigatti I, et al. Estimates of the severity of coronavirus disease 2019: a model-based analysis. Lancet Infect Dis. https://doi.org/10.1016/S1473-3099(20)30243-7.

19. Riou J, Althaus CL. Pattern of early human-to-human transmission of Wuhan 2019 novel coronavirus (2019-nCoV), December 2019 to January 2020. Euro Surveill. 2020;25(4):2000058.

20. Riou J, Althaus CL. Pattern of early human-to-human transmission of Wuhan 2019 novel coronavirus (2019-nCoV), December 2019 to January 2020. Eurosurveillance. 2020;25(4):2000058.

21. Oliphant TE. Python for scientific computing. Comput Sci Eng. 2007;9(3):10-20.

22. Hunter JD. Matplotlib: a 2D graphics environment. Comput Sci Eng. 2007;9(3):90-5.

23. The World Bank. The World Bank Data: Hospital beds (per 1,000 people). 2020. https://data.worldbank.org/indicator/SH.MED. BEDS.ZS. Accessed 30 Mar 2020.

24. Kissler SM, Tedijanto C, Goldstein E, Grad YH, Lipsitch M. Projecting the transmission dynamics of SARS-CoV-2 through the postpandemic period. Science. 2020;2020:eabb5793.

25. Tuite A, Fisman DN, Greer AL. Mathematical modeling of COVID-19 transmission and mitigation strategies in the population of Ontario, Canada. medRxiv 2020. https://doi.org/10.1503/ cmaj.200476

26. Prem K, Liu Y, Russell TW, et al. The effect of control strategies to reduce social mixing on outcomes of the COVID-19 epidemic in Wuhan, China: a modelling study. Lancet Public Health.

27. Xu S, Li Y. Beware of the second wave of COVID-19. Lancet. 2020;395(10233):1321-1322 
28. Chang SL, Harding N, Zachreson C, Cliff M, Prokopenko O M. Modelling transmission and control of the COVID-19 pandemic in Australia. arXiv 2020; (2003.10218).

29. Bard J. Analysis of biological networks. J Anat. 2009;215(4):473.
30. Marais BJ, Williams S, Li A, et al. Improving emergency preparedness and response in the Asia-Pacific. BMJ Glob Health. 2019;4(1):e001271.

\section{Affiliations}

\section{Rajiv Chowdhury ${ }^{1}$ (D) Kevin Heng ${ }^{2,3} \cdot$ Md Shajedur Rahman Shawon $^{4} \cdot$ Gabriel Goh $^{5}$. Daisy Okonofua ${ }^{1}$. Carolina Ochoa-Rosales ${ }^{6,7}$. Valentina Gonzalez-Jaramillo ${ }^{8}$. Abbas Bhuiya ${ }^{9} \cdot$ Daniel Reidpath $^{10}$. Shamini Prathapan ${ }^{11}$. Sara Shahzad ${ }^{1}$. Christian L. Althaus ${ }^{8} \cdot$ Nathalia Gonzalez-Jaramillo $^{8}$. Oscar H. Franco ${ }^{8}$ on behalf of The Global Dynamic Interventions Strategies for COVID-19 Collaborative Group}

Rajiv Chowdhury

rc436@medschl.cam.ac.uk

$\triangle$ Oscar H. Franco

oscar.franco@ispm.unibern.ch

1 Department of Public Health and Primary Care, School of Clinical Medicine, University of Cambridge, Cambridge, UK

2 Center for Space and Habitability, University of Bern, Bern, Switzerland

3 Department of Physics, Astronomy and Astrophysics Group, University of Warwick, Coventry, UK

4 Centre for Big Data Research in Health, University of New South Wales, Sydney, Australia

5 OpenAI Artificial Intelligence Research Laboratory, San Francisco, CA, USA
6 Department of Epidemiology, Erasmus MC - University Medical Center Rotterdam, Rotterdam, The Netherlands

7 Centro de Vida Saludable, Universidad de Concepción, Concepción, Chile

8 Institute of Social and Preventive Medicine, University of Bern, Bern, Switzerland

9 Independent health and population researcher, Dhaka, Bangladesh

10 International Centre for Diarrhoeal Disease Research, Dhaka, Bangladesh

11 Department of Community Medicine, University of Sri Jayewardenepura, Colombo, Sri Lanka 